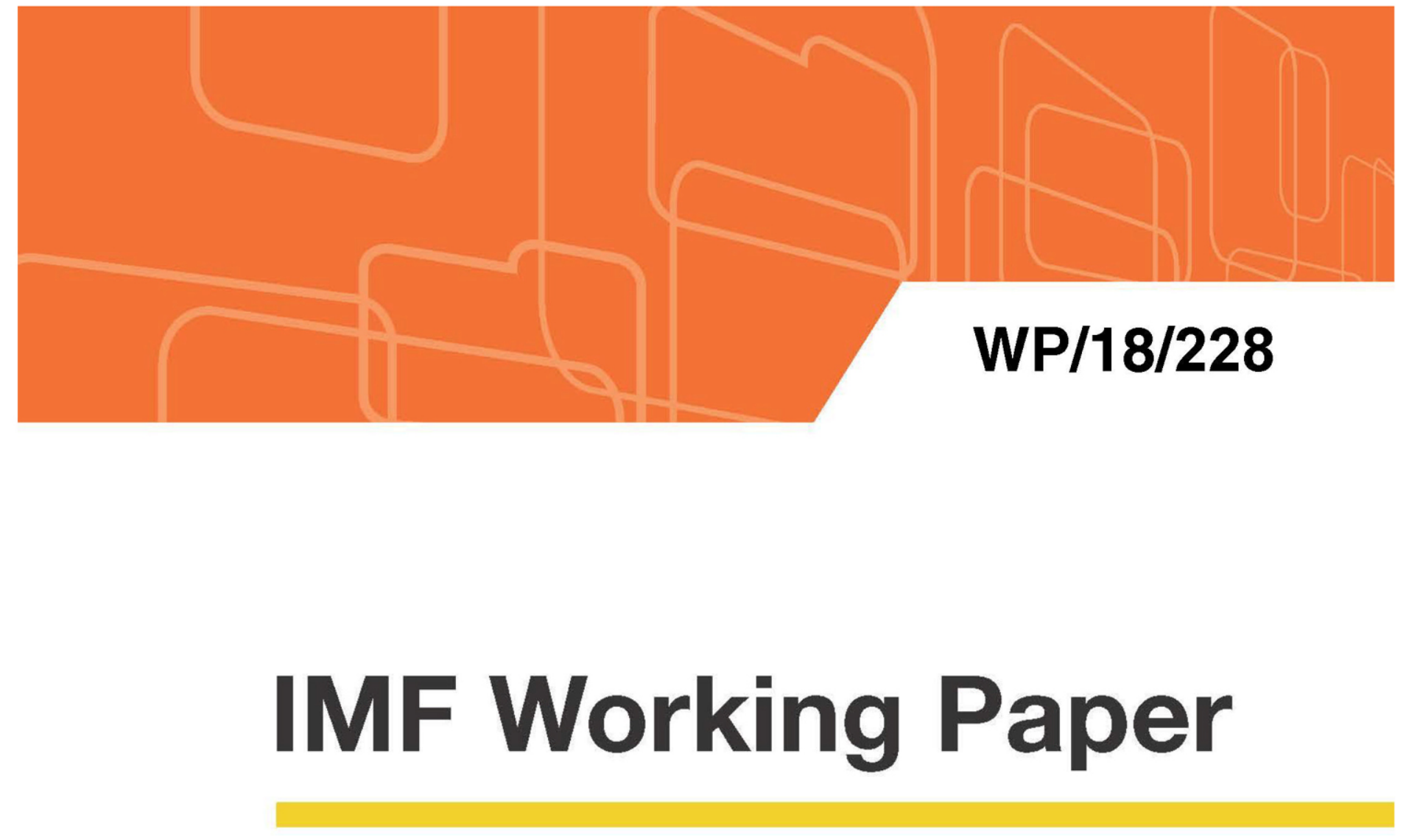

\title{
The Morning After-The Impact on Collateral Supply After a Major Default
}

by Dermot Turing and Manmohan Singh

IMF Working Papers describe research in progress by the author(s) and are published to elicit comments and to encourage debate. The views expressed in IMF Working Papers are those of the author(s) and do not necessarily represent the views of the IMF, its Executive Board, or IMF management. 


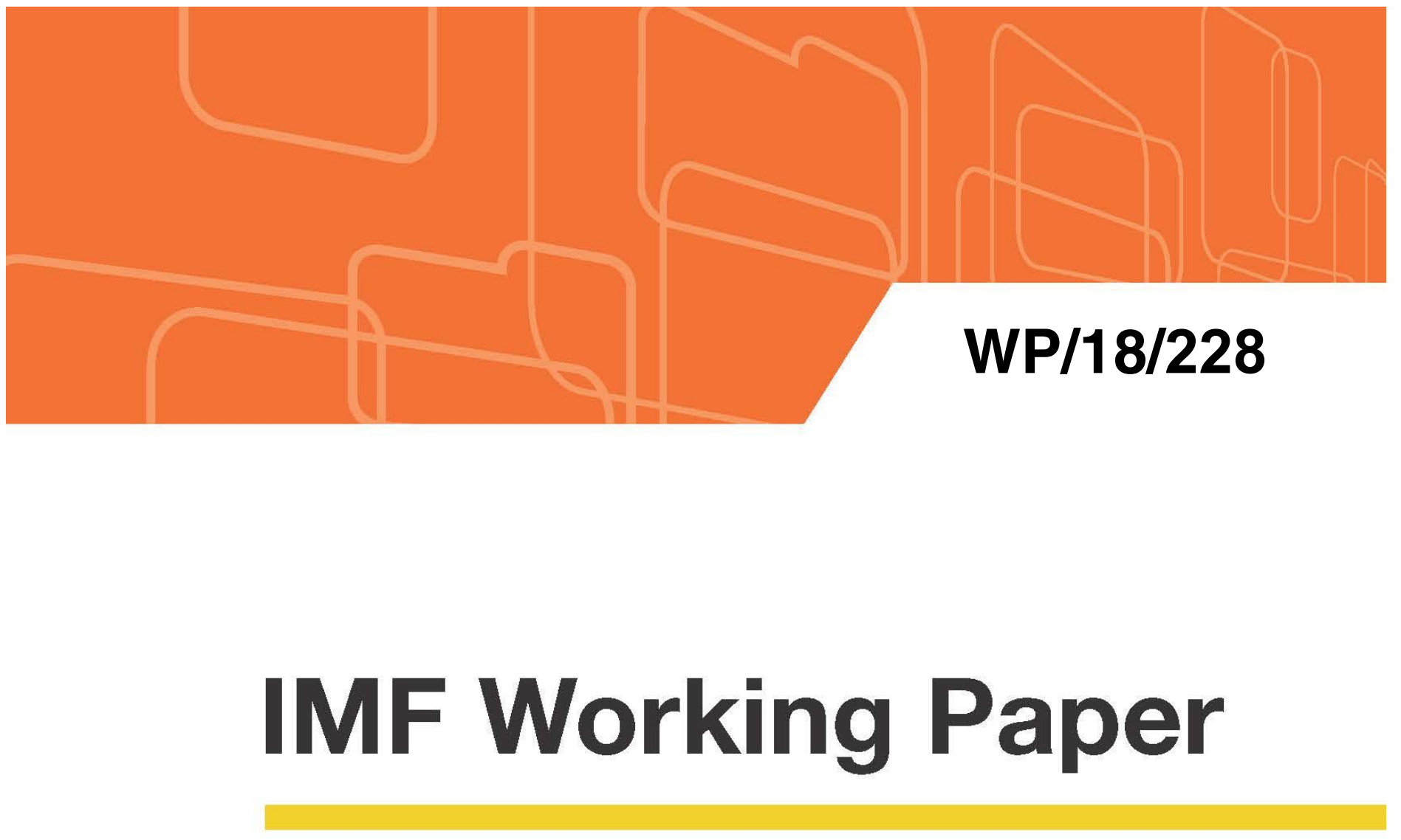

\section{The Morning After-The Impact on Collateral Supply After a Major Default}

by Dermot Turing and Manmohan Singh

IMF Working Papers describe research in progress by the author(s) and are published to elicit comments and to encourage debate. The views expressed in IMF Working Papers are those of the author(s) and do not necessarily represent the views of the IMF, its Executive Board, or IMF management. 


\title{
IMF Working Paper
}

Monetary and Capital Markets Department

\section{The Morning After-The Impact on Collateral Supply After a Major Market Default}

\section{Prepared by Dermot Turing and Manmohan Singh ${ }^{i}$}

Authorized for distribution by Gaston Gelos

October 2018

\section{IMF Working Papers describe research in progress by the author(s) and are published to elicit comments and to encourage debate. The views expressed in IMF Working Papers are those of the author(s) and do not necessarily represent the views of the IMF, its Executive Board, or IMF management.}

\begin{abstract}
Changes to the regulatory system introduced after the financial crisis include not only mandatory clearing of OTC derivatives at central counterparties and margining of uncleared derivatives, but also prudential measures, including notably a "Liquidity Coverage Ratio" which obliges firms to set aside high-quality liquid assets (HQLA) as a stopgap against anticipated cash outflows. We examine factors which may affect the demand for HQLA in a severely stressed market following a hypothetical default of a major clearing member. Immediately following a major default, the amount of HQLA demanded by the whole market would spike. We estimate the size of the spike and draw conclusions as to whether the depth of the market is adequate to absorb it.
\end{abstract}

JEL Classification Numbers: G21, G28, F33, K22, G18, G15

Keywords: HQLA, clearing, liquidity, derivatives, default, CCPs, liquidity coverage ratio, VMGH, initial margin

Author's E-Mail Address: msingh@imf.org; dermotturing@btinternet.com

\footnotetext{
i This paper was presented at the $5^{\text {th }}$ Joint Bank of Canada and Payments Canada workshop held in Ottawa, September 20-21, 2018. We thank Pierpaolo Grippa and Caio Ferreira for feedback and comments.
} 


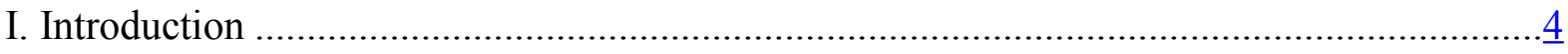

II. OTC Derivatives and HQLA in Stressed Markets ..........................................................

III. Test Scenario in a Post-Default Environment..................................................................

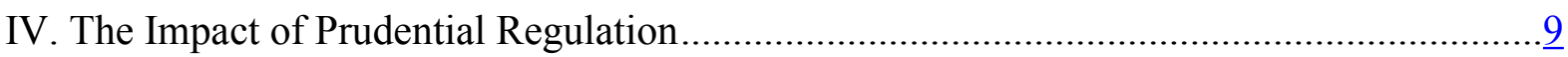

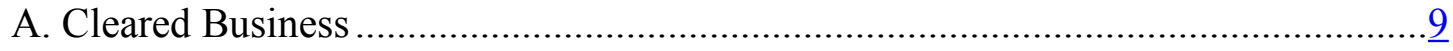

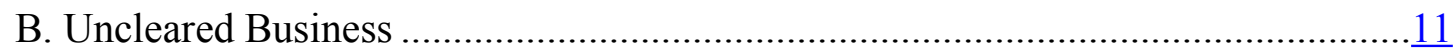

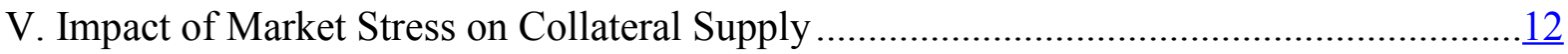

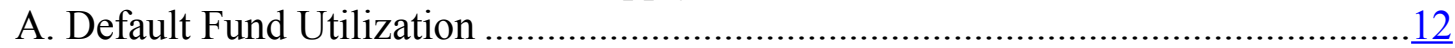

B. Initial Margin Increases..............................................................................

C. Loss of Receipts: Defaulted Master Agreements .................................................14

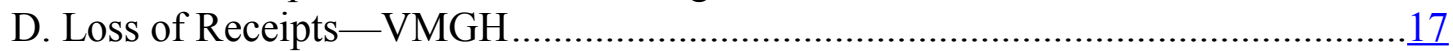

E. Overall Impact of the Default on HQLA Requirements ........................................18

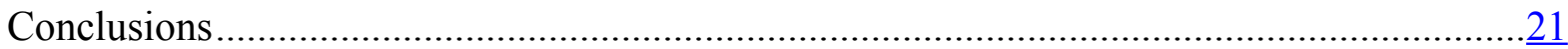

Tables

1. LCR Impact of Altered Margin Behavior Following Default ……………………...........12

2. Effect of Major Default on HQLA Requirements …………...........................................19

Box

1. The Demand/Supply of Global HQLA — the Macro Picture via Collateral Reuse Rate.......20

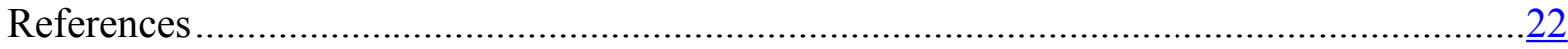




\section{INTRODUCTION}

The amount of attention paid by regulatory authorities to over-the-counter (OTC) derivatives has increased markedly since the financial crisis of 2008. Various initiatives have affected the way that OTC derivatives must be handled by the transaction parties once the transaction has been agreed. Notable among these are the obligations to clear at a central counterparty (CCP) derivative trades which are eligible for clearing, and to provide collateral (initial margin ${ }^{1}$ ) to the counterparty in other cases. The Group of Twenty's program for reform, introduced after the crisis, included the direction that all standardized OTC derivatives should be cleared through CCPs, and that non-centrally-cleared derivatives should be subject to margin requirements (G-20, 2009; G-20, 2011).

We assess the effect of the demand for high-quality liquid assets (HQLA) which may be made in the context of a market experiencing the after-shocks of a major default. We find that significant impact could arise from increases in initial margin demands and loss of gains which would ordinarily flow through variation margin, and in particular the way in which prudential regulation affects clearing members' liquidity coverage requirements. These factors, taken together, could subject the collateral markets to further substantial stress. The topology and network of the OTC derivative market has (and continues) to change. Thus, it will be useful to show analytics that support the transition to clearing and the bifurcation of the OTC derivative market (between clearing and bilateral) and if this reduces taxpayer support relative to 2008 .

The object of this paper is to assess the impact of prudential regulation on non-defaulting clearing members of a major default among their peer group. Various prudential regulatory measures will be implicated. Our analysis indicates that, of the regulatory influences, the most significant impact for clearing members will arise as a consequence of the liquidity coverage obligations imposed under Basel III (BCBS, 2015), though this must be viewed in the wider overall context of other demands on clearing members following a big default. Accordingly, we also assess the size of the regulatory influences relative to the other challenges facing market participants, in particular as regards the demand for collateral. We conclude that the demand for collateral arising from relatively new prudential rules is manageable, and that variation margin gains haircutting (as a strategy for a CCP to restore itself) is not unduly disruptive.

Much research and debate has taken place on the optimum structure of a CCP's waterfall (for example, Nahai-Williamson et al., 2013; Cont, 2015; Perkins et al., 2016; Murphy, 2017; Huang, 2017; J.P. Morgan, 2017; Capponi et. al., 2018). Recently, attention has turned to end-of-waterfall scenarios, the tools available to a CCP for restoring itself to financial health, and the ideas of "recovery" and "resolution" as applied to a CCP (for example, Tucker, 2013; Duffie, 2014; ISDA, 2017; Singh and Turing, 2018; and a range of official proposals:

European Commission, 2016; CFTC, 2016; CPMI, 2017; FSB, 2016, 2017). This paper looks at collateral needs arising during stress. We do not re-open the discussion about the adequacy

\footnotetext{
${ }^{1}$ Initial margin is provided to cover against potential future losses after early termination (close-out) of a contract, incurred between the point of default and the eventual settlement of the contract (the margin period of risk). Initial margin is typically exchanged at the inception of the contract but may be adjusted during its lifetime to reflect changed market conditions. Initial margin is provided unidirectionally, to the CCP, in relation to cleared contracts, and bidirectionally in relation to uncleared contracts. Variation margin is provided and adjusted more frequently, typically daily, in order to reflect changes in the value of the contract to one party or the other since the last adjustment of variation margin.
} 
of CCPs' resources to manage defaults: it is taken as given that such a scenario as we discuss would arise only in highly unusual circumstances.

This paper is organized as follows. In section II, we briefly review the background relating to derivatives, clearing and stressed markets. Section III presents a scenario following default of a major clearing member, which we use for our analysis, in section IV, of prudential regulatory metrics in that context. In section $\mathrm{V}$ we estimate the demand for HQLA which could arise. Section VI concludes.

\section{OTC DERIVATIVES ANd HQLA IN STRESSED MARKETS}

Since the financial crisis it has been generally accepted that clearing via a CCP is a vital component of financial stability. CCPs have a range of resources on which to call to ensure that the non-defaulting clearing members continue to receive performance on their cleared transactions. The options are initial margin (collateral provided by a clearing member to support its own obligations), "skin-in-the-game" (resources provided by the CCP itself from reserves or capital, dedicated to loss-absorption), the default fund (provided as a mutualized resource by clearing members to be utilized upon a default), capital (invested by the owners of the CCP) - these elements comprising the "waterfall" available to cover losses - and contingency arrangements for loss-allocation at the end of the waterfall.

Given that the rationale of the post-crisis reforms is greater stability in the event of a counterparty failure, it is appropriate to examine the impact on the clearing members of a major financial institution default.

Accordingly, our analysis looks at a major shock where the entire waterfall of the CCP is exposed, so that loss-allocation arrangements may come into play. In these rather extreme circumstances, liquidity is the key parameter for clearing members (Cont, 2017) as well as for CCPs (Baker, 2012; Turing, $2016 \$ 17.59$ ). Shocks may propagate through the system, notwithstanding the interposition of the CCP (Bardoscia et al, 2018). Clearing members' ability to finance CCPs' demands for contingency funding, as per the rulebooks of the CCPs, may be impaired (Armakolla and Laurent, 2017).

Liquidity should not be viewed as simply a matter of cash or money supply. Collateral (HQLA) and cash are intricately intertwined, with financial institutions such as clearing members making free use of either to meet their liquidity needs (Singh, 2010, 2014).

Restricting collateral re-use has been in regulatory vogue since the frauds of Madoff and reinforced following the crisis: in the United States the Securities Exchange Act of 1934 and SEC rule 15c3-3, rehypothecation of collateral is limited to 140 percent of the collateralized liability, but in other geographies no such restriction existed before the Madoff frauds. However, re-use is now limited: to give two examples, as regards market participants taking collateral, under the EU Securities Financing Transactions Regulation, ${ }^{2}$ or as regards CCPs under EMIR. ${ }^{3}$ Unlike cash, clearing members will be constrained in their ability to recycle HQLA which comes into their hands. ${ }^{4}$

\footnotetext{
${ }^{2}$ Regulation (EU) 2015/2365, articles $15 \mathrm{ff}$.

${ }^{3}$ Regulation (EU) 648/2012, articles 39(8), 47.

${ }^{4}$ CFTC in the U.S. has recently softened its stance on segregation; this will encourage re-use.
} 
Restricting re-use is a tight money policy that seems to be at odds with the current policies of key monetary authorities. Money metrics such as M0, M1, M2 should integrate the sizable pledged collateral metrics (i.e., a combination of $\mathrm{M} 0+\mathrm{C} 0 \ldots \mathrm{M} 2+\mathrm{C} 2$, etc.) into thinking on financial lubrication. The underlying economics of pledged collateral reuse is similar to the reuse of deposits in the banking system. Incorporating the amount of "source collateral," with balance sheet footnote data of large banks, the collateral reuse rate (or, collateral velocity) can be approximated, and it declined from about three as of end-2007 to below two as of end2016. In fact, pledged collateral used in financial transactions is probably at par with money, especially if all money does not flow towards market transactions.

Thus, the impact on the "collateral supply" of a major default in the market deserves analysis. In the first place, it may be observed that the collateral supply is affected by the obligation to clear OTC derivatives (Singh, 2010; Koeppl, 2012; Singh, 2013). A similar consequence can be expected from the incipient obligation of parties to uncleared OTC derivatives transactions to support those transactions by providing initial margin, in the form of HQLA, to their counterparties (with no netting and no possibility of rehypothecation) (BCBS, 2015). ${ }^{5}$ As yet, though, there is only limited analysis of the impact of this new requirement (cf. Cont, 2018).

The final development to which we draw attention is the introduction of new prudential regulatory standards in the Basel III framework applicable to banks and investment firms, to which class clearing members belong. Basel III added liquidity metrics to the existing rules concerning capital adequacy, large exposures, operational risk, etc. (BCBS, 2013, paragraph 119). ${ }^{6}$ These include a "liquidity coverage ratio (LCR)." In simplified terms, the LCR obliges a bank to hold HQLA to be liquidated in the event of a rainy-day liquidity shock such as the classic "run on the bank." So, the bank must compute its potential net cash outflows in a time of stress, and hold a given level of HQLA in line with the net outflow. Regulatory standards prescribe the amount of outflow which the bank must presume will occur. In the following section, we show that the amount of presumed outflow increases markedly in a highly-stressed end-of-waterfall market scenario, with the result that the demand on the market for HQLA will also increase markedly as banks seek to comply with their LCR obligations.

\section{Test Scenario in a Post-Default EnVIronment}

We postulate a situation of market stress following a major default. In a post-default scenario, three changes will have to be handled simultaneously by a non-defaulting clearing member:

- the actions of the CCP which is handling the default:

- $\quad$ the clearing member's bilateral uncleared portfolio of transactions with the defaulter, which ordinarily will be closed out; and

- the clearing member's bilateral uncleared portfolios of transactions with other nondefaulting market participants, which will presumably continue.

\footnotetext{
${ }^{5}$ Also, European Commission Delegated Regulation 2016/2251.

${ }^{6}$ Also, Regulation (EU) 575/2013, arts 420ff.
} 
Beginning with the CCP's actions: in managing a particularly difficult default, a CCP is obliged to try to re-establish a matched book in respect of trades in the defaulter's account, by arranging the auction and transfer (where the auction is successful) of the defaulter's transactions to non-defaulting clearing members, and disposal of collateral into the market. However, in a very difficult default, it is not a given that these processes will have a successful outcome. A successful auction will depend on the bidders making "realistic" bids, which might not happen in stressed market conditions; or the bids may be so far away from the CCP's view of what is expected that the best bid is not accepted. Such an outcome implies that the entire default waterfall of the CCP is at risk: the best bids received may exceed the available resources. The CCP may have to find alternative ways of holding the defaulter's position, while maintaining its own obligations to surviving clearing members. In practice that may not be achievable without tear-up of cleared positions or variation margin gains haircutting, as discussed below.

It is noted by some writers that an end-of-waterfall scenario is not fanciful (for example, Lin and Surti, 2013; Paddrik and Young, 2017; Capponi et al., 2018). Cont (2017) argues that "commonly used market risk measures such as $\mathrm{VaR}$ or $\mathrm{ES}^{7}$ do not yield a proper evaluation of liquidation costs ... the cost of unwinding large portfolios can be quite high and exceed several multiples of the VaR ... the liquidation cost is proportional to the gross notional size." (We note that the gross notional (open interest) for LCH.Clearnet Limited (LCH), the operator of SwapClear, is US\$164 trillion, a figure which may be compared to the resources immediately available for default coverage in the case of a typical SwapClear clearing member of US\$11.65 billion. ${ }^{8}$ The comparable figures for CME are US\$16 trillion and US\$5.78 billion (LCH and CME published data; Khwaja, 2018).)

The scenario under examination assumes that we are concerned only with the clearing of OTC derivatives, and that one or more major clearing members of the CCP have failed, leaving the CCP with an unmatched book (and/or losses) on closed-out positions which exceed the resources available in the traditional default waterfall. We predict that the impact of a major default, where the auction process fails to give acceptable, or any, valuations enabling the defaulter's portfolio to be closed out, could thus impinge on a clearing member in the following ways:

- $\quad$ An increase in the level of initial margin required to support the non-defaulters' cleared portfolios. Various authorities observe that spikes in initial margin demands could be softened through more conservative business-as-usual margin policies (IMF, 2007; CGFS, 2010; Miglietta et al, 2015). In relation to cleared business, that involves the allocation of losses between defaulter pays (initial margin) and survivors pay (default fund) philosophies. We conclude that hikes in initial margin requirements by CCPs cannot be ruled out.

- Use of the default fund contributions of not just the defaulter but also the nondefaulting members may occur. CCPs have "assessment" rules which oblige the non-

\footnotetext{
${ }^{7} \mathrm{VaR}$ stands for "value at risk," meaning the estimated amount which may be lost if the contract is terminated and the counterparty is unable to pay any amount owing. ES stands for "expected shortfall" and is, essentially, a different measure of the same variable.

${ }^{8}$ Average single member's Initial Margin amount + CCP's own contributed "skin in the game" + entire default fund.
} 
defaulting members to replenish the default fund, so that the CCP has a full complement of resources in order to continue in business with due compliance.

- One solution to the failed auction is the tearing-up, wholly or in part, of transactions so as to neutralize the defaulter's portfolio. This is challenging, because it requires valuation, and in our postulated scenario the valuation machinery is not effectively functioning (cf. Singh and Turing, 2018).

- The remaining tool, which may work (Heath et al, 2015), is withholding variation margin payments due to in-the-money non-defaulting members (VMGH). The implementation of a period of VMGH will affect a clearing member's liquidity. The intention of $\mathrm{VMGH}$ is to supply the CCP with an inflow of cash from clearing members in respect of each portfolio which moves out of the money. Variation margin is typically collected at least daily from such clearing members; in untroubled conditions the variation margin is then passed straight out to the holders of portfolios which have moved into the money, so the CCP itself is left with zero net change. However, when VMGH is invoked, the gainers (holders of net in-the-money accounts) do not receive their gains, which are retained irrevocably by the $\mathrm{CCP}$ as an increment to funds to be utilized for default management. The "gainers" thus lose their gains, while the out-of-the-money losers continue to fulfil their obligations. ${ }^{9}$ Our scenario imagines that $\mathrm{LCH}$, the largest clearer of derivatives, but no other $\mathrm{CCP}$, has implemented VMGH.

At this point, we should observe that clearing members do not exclusively clear their own transactions. They act as service providers for clients as well. However, we would expect the impact of a major default to be limited, as far as the clearing member is concerned, as a result of clearing clients' positions. This is because clearing members will typically have a "pay-aspaid" clause in their business terms with clients, which enables them to pass on losses on client positions; there are derogations from prudential regulatory rules when such clauses are in place, so that losses (such as VMGH) are likely to be passed on down the chain to the client. ${ }^{10}$ The impact on the client may, of course, be severe, but our scenario analysis focuses on the clearing member.

Looking next at the uncleared portfolios, ordinary default management planning assumes that any transactions between a non-defaulter and the failed market participant will be closed out, subject to the constraints imposed by recovery and resolution overrides, ${ }^{11}$ under wellunderstood and tested procedures set out in standard market documentation. Collateral would be liquidated to cover losses. Once the process is complete, any net loss attributable to the relationship with the defaulter will have limited ongoing prudential impact for the nondefaulting market participants apart from the deduction from capital which would also be the result of any loss. Whether in practice is this achievable depends on the market liquidity for the instruments being closed out. That might not be taken for granted in a market

\footnotetext{
${ }^{9}$ We assume that variation margin is structured as a "settlement payment" not collateral.

${ }^{10}$ Cf Regulation (EU) 575/2013, Article 306.

${ }^{11}$ Under typical recovery and resolution regimes, market counterparties (but not CCPs) will be stayed for up to two business days in effectuating close-out action, in order to give resolution authorities an opportunity to put a resolution plan into action.
} 
environment where a $\mathrm{CCP}$ is engaged in VMGH: because such an environment is one where the ordinary auction process, activated by the CCP as part of its own default management plan, has failed to produce acceptable bids or has failed entirely. That outcome implies dysfunction on the part of the market, which could impair bilateral close-out valuations just as it impaired the CCP's default management process.

A non-performing uncleared derivatives portfolio will accumulate market risk without the benefit of a variation margin flow. Accordingly, the risk flowing from an illiquid market where close-out is similar in shape, if not in size, to the implementation of VMGH in respect of a cleared portfolio.

Finally, we consider the remaining part of a non-defaulter's uncleared derivatives portfolio, namely the various transaction sets in place with other non-defaulters in the market. These will, presumably, carry on; but as with cleared transactions, we would foresee an increase in initial margin obligations (on both sides of each portfolio). Initial margin increases have historically followed defaults (Brunnermeier and Pedersen, 2009; IMF, 2007; CGFS, 2010). The amount of collateral required to be provided to transaction counterparties on uncleared trades may be affected by two factors following a major default. In first place, haircuts will be adjusted to reflect impaired values. Collateral values could be affected by the "fire sale" effect of counterparties' (including CCPs) attempts to realize their security. If a tightening of the market - depression of market-making activity to below-normal levels, such as was observed following the Lehman default - occurs, haircuts would increase, and additional collateral will be required to support an existing portfolio of transactions. Secondly, insofar as transactions themselves require revaluation (which may be the case, for example, where credit values are a factor in the transaction) the potential future exposure under transactions may rise, requiring further margin to be posted.

\section{The Impact of Prudential Regulation}

The introduction of legal requirements to clear certain types of product, such as interest rate swaps and credit derivatives, has been accompanied by special treatment under prudential regulatory rules. On the whole, the special treatment is designed to incentivize clearing, rather than to establish parity of treatment between the uncleared and cleared worlds.

Previous studies on clearing member behavior and incentives (Carter and Garner, 2015; Murphy, 2017; J.P. Morgan, 2017; Capponi et al, 2017) have not looked at the impact of prudential regulation in the period when a CCP is handling a particularly difficult default. This paper analyses the effect of prudential regulatory standards on surviving clearing members and the supply of HQLA during that period.

\section{A. Cleared Business}

At least eight different prudential metrics could bear on a clearing member's cleared business. Some of these would not be affected at all by the implementation of a default management regime by the CCP. ${ }^{12}$ Some other metrics would be affected, but only in a moderate way: capital requirements for counterparty risk (facing the $\mathrm{CCP}$ in respect of the

\footnotetext{
${ }^{12}$ Capital requirements for counterparty risk on the clearing member's exposure to the CCP as regards client transactions, operational risk and CVA risk, large exposures rules and the leverage ratio.
} 
clearing member's own-account book and facing clients) and leverage ratio. Furthermore, the utilization of the surviving clearing member's default fund contribution will constitute a deduction from its regulatory capital. Using LCH 2018 data: the top 10 clearing members contribute on average 3.1 percent of the default fund, so capital requirement uplift for a surviving clearing member, resulting from loss of its contribution to the fund, is probably limited to about 10 percent, or US\$1.7 million, which ought to be easy to bear. A more important point is that Basel III metrics do not recognize the CCP as an impaired credit after utilization of the default fund, so the CCP's trouble is not visited upon the capital adequacy requirements of its risk-capital providers (viz the clearing members).

Some metrics, however, appear to be affected more substantially. Notably, VMGH could have a significant effect on position risk (as capital charges relate to market risk). For so long as the CCP is excused paying gains to the clearing member, the clearing member is left with an unhedged position which will increase its position risk requirement on its house book. So, the clearing member's capital requirement will be increased while the $\mathrm{CCP}$ is in crisishandling mode.

The most significant impact on firms, though, will be due to the rules on liquidity coverage. To reiterate, under prudential standards, the clearing member has to assess its expected cash outflows over the next 30 days and hold HQLA to cover the expected net outflow. Following a major default, cash-flows are affected in the following ways:

- Utilization, or even future expected utilization, of the default fund will give rise to a replenishment obligation for surviving clearing members. That cash outflow will now be expected to occur within the 30-day timeframe, whereas before the default it could be disregarded as a remote contingency. Accordingly, a liquidity coverage requirement will immediately arise in respect of the CCP's likely demand for replenishment during the coming 30 days.

- Increases in initial margin demanded by the CCP will not only have to be met but can trigger an increment to the liquidity coverage obligations of the clearing member. This is because Basel III rules oblige collateral-providers to retain HQLA of 20 percent of the value of initial margin posted (BCBS, 2013, paragraph 119), insofar as posted collateral does not consist of "level 1" assets. ${ }^{13}$ The rules are a safeguard against revaluation of collateral already posted; the effect in the very short term is that each margin hike has a real impact of more than 100 percent of the additional margin called.

- $\quad$ A period of VMGH will have a side-effect due to the LCR requirements affecting firms expecting future cash inflows. Where cash inflows (such as variation margin) are impaired due to "non-performance by the counterparty" - a phrase which aptly describes the action of a CCP applying VMGH - those inflows can no longer be counted by the clearing member as legitimate inflows helping satisfy its liquidity requirement. The clearing member must then evaluate the likely duration of the period of VMGH, up to 30 days ahead, and the consequent reduction of its liquidity inflow.

\footnotetext{
${ }^{13}$ Also, Regulation (EU) 575/2013, Article 423. Securities which comprise "level 1" assets are essentially highly-rated sovereign debt instruments, plus some other exceptional cases (see European Commission Delegated Regulation 2015/61, article 10). Much of the collateral posted to CCPs is likely to be "level 1."
} 
The gap will have to be made up by acquiring HQLA, unless the clearing member has identified some saving of outflows. (On cleared client business, where the client is not affiliated to the clearing member, it is likely that the clearing member will not have to pass on variation margin which it has not received, so to a degree that may be the case. ${ }^{14}$ ) Thus, to the extent of its "house" (including affiliated client) cleared business, a forward view of lost variation margin will have to be immediately covered by HQLA.

\section{B. Uncleared Business}

As regards derivatives transactions which are not cleared, prudential regulatory metrics are similar to those applicable to cleared transactions, albeit with differences of implementation. In relation to a firm's uncleared portfolio where the defaulter was its market counterparty, the survivor will have attempted to close out the relevant master agreements and realize collateral it holds to address any loss. However, if close-out is impaired, as described above, by a difficult market in which it is not immediately feasible to price accurately the defaulted portfolio, this ideal outcome may not happen. (Given that the uncleared portfolio represents the more complex, less standardized transactions, a market failure experienced by the $\mathrm{CCP}$ in relation to standardized products is all the more likely to be experienced by a bank trying to price unstandardized transactions in the same conditions.) The result will be that the surviving firm has to hold the non-performing portfolio, without the benefit of any variation margin receipts from the defaulted counterparty. That will have a similar prudential effect, in terms of liquidity coverage requirements, to the implementation of VMGH by the CCP. The firm must take a view on the likely loss of inflow over the coming 30 days and factor that into its overall cashflow calculation and cover the shortfall with HQLA.

The remaining analysis of uncleared derivatives transactions focuses on the continuing transactions between a non-defaulter and other survivors. The principal issues for such transactions in a stressed market will be an increase in the capital requirement, caused by the widening of spreads in the credit market which will directly impact the CVA charge, and, more significantly, the effect on the surviving institution's collateral liquidity.

Recently introduced regulation obliges market participants to provide initial margin to their counterparties in respect of uncleared transactions (BCBS, 2015). ${ }^{15}$ It will be recalled that each party must provide collateral, in the form of HQLA, as initial margin, to the other. The amount of collateral is based on a calculation of the potential future exposure on the portfolio, assuming a 10-day margin period of risk. No general rehypothecation of the collateral is permitted, so the collateral taker must lock it away; and no offsetting of collateral obligations is permitted either, so the collateral flows are gross. In the event of changed market conditions, the amount of collateral transferred must be re-evaluated. As with initial margin provided to the CCP, it seems that the effect of a major default will be to increase initial margin obligations in the uncleared space, with similar results.

\footnotetext{
${ }^{14} \mathrm{We}$ assume that clearing members will include 'pay-as-paid' clauses in their customer terms, which means that variation margin cuts will be "passed on" (i.e., variation margin will not be paid to client gainers), leaving the clearing member no worse off.

${ }^{15}$ Also, European Commission Delegated Regulation 2016/2251.
} 


\section{IMPACT OF MARKet Stress ON COLlateral SUPPly}

It would appear that, in a period following an extreme default, surviving clearing members will experience unusual, and probably unplanned-for, need for HQLA to satisfy a number of immediate and simultaneous demands:

- $\quad$ Cash or HQLA will be needed immediately, against a likely early demand to replenish the default funds of affected CCPs. While the clearing member is waiting for the CCP to send out its "assessment demand" (the calls for replenishment of the default fund, following utilization of the non-defaulters' contributions in part or in whole), the expected assessment must be backed dollar-for-dollar by HQLA.

- Initial margin hikes will impose a requirement for HQLA, scaled up by a further 20 percent in the case of collateral which is not comprised of "level 1" assets to cater for the LCR impact of collateral provided in respect of derivatives transactions.

- $\quad$ Expected variation margin receivable in respect of the cleared, and the uncleared defaulted, portfolios, will not be received. Under VMGH, the issue is for "gainers" who must forgo their gains; in the uncleared domain, the issue is for counterparties of the defaulter, who will hold zombie portfolios of unvalued transactions. In both instances, less cash is flowing into the firm, necessitating increased levels of HQLA held for liquidity coverage.

Table 1. LCR Impact of Altered Margin Behavior Following Default

\begin{tabular}{lll}
\hline & \multicolumn{1}{c}{ Initial Margin } & \multicolumn{1}{c}{ Variation Margin } \\
\hline Cleared portfolio & $\begin{array}{l}\text { Increased IM requirement. } \\
\text { Additional 20 percent on some assets } \\
\text { due to LCR. }\end{array}$ & $\begin{array}{l}\text { VM receipts witheld by CCP. } \\
\text { LCR requires forward } \\
\text { summation of lost receipts. }\end{array}$ \\
& $\begin{array}{l}\text { Increased IM requirement on master } \\
\text { agreements with surviving } \\
\text { counterparties. }\end{array}$ & $\begin{array}{l}\text { VM receipts non-performing on } \\
\text { master agreement with } \\
\text { defaulter. }\end{array}$ \\
& Additional 20 percent due to LCR. & $\begin{array}{l}\text { LCR requires forward } \\
\text { summation of lost receipts. }\end{array}$ \\
\hline
\end{tabular}

Source: IMF staff estimates.

Our enquiry now turns to the quantum of these demands, and the extent to which they may be mitigated by the release into the market of collateral assets held by CCPs and other nondefaulting counterparties of the defaulter following regular close-out and liquidation activity.

\section{A. Default Fund Utilization}

Although our hypothetical default scenario caused a major problem at a single CCP, it seems likely that the same default will need to be managed by numerous CCPs. The world's largest clearing members participate in many CCPs (see the network diagrams in Bank of England, 2016 and Markose et al., 2017). The default fund at LCH is US\$6.7 billion; the total amount 
of commitments given by clearing members across the population of CCPs is approximately US\$75 billion (Khwaja, 2018). ${ }^{16}$ We note that it is improbable that even a major default would wipe out the default funds of all CCPs - which clear a variety of different cash-market, exchange-traded, and OTC products-simultaneously; so we do not regard it as likely that there would be a drain of HQLA, due to default fund replenishments, of that magnitude. But we do consider that the figure of US 6.7 billion (single CCP, if we take LCH as our example, with a single top-up) may be too conservative. If we limit the putative worst-case figure to a single replenishment in full of the default funds of four CCPs which clear derivative products (LCH, CME, ICE, and Eurex) the amount at stake is approximately US\$22 billion (Khwaja, 2018). ${ }^{17}$

It may be a possibility for clearing members to liquidate non-HQLA assets and to utilize the proceeds to satisfy a default fund top-up demand, but the liquidity of markets for such assets in an extreme scenario such as that under consideration is difficult to predict. We have therefore not analysed this possibility.

\section{B. Initial Margin Increases}

Assuming margin to increase with market volatility, initial margin increases are likely following a default. Various studies enable an estimate to be made of the possible level of initial margin increases in a time of stress. CGFS (2010, Table 1) charted the changes in haircut in securities financing transactions over the period June 2007-June 2009, that is to say from the emergence of the sub-prime market issues through the ensuing financial crisis including the failures of Bear Stearns, Lehman and AIG. The haircuts applicable to HQLA increased in the range 0.5 percent to 7 percent. CGFS (2010, Box 1) also has an example of a single margin call representing a 3.5 percent increase in margin. Miglietta et al (2015) observed a hike of 3.5-5 percent in initial margins during the Eurozone crisis of November 2011. LCH and CC\&G raised margins on HQLA by 3.5-5 percent, with some collateral being hiked by as much as 9-14 percent. On average, a 5 percent increase was observed across the range of maturities of collateral assets (Corradin et al., 2017).

Initial margins posted to CCPs are estimated to be US\$500 billion (Khwaja, 2018), and looking just at margin posted for cleared interest rate and credit derivatives, US\$194 billion (ISDA, 2018). Clearing volumes will increase with the continuation of the (only just begun, in 2018) implementation of mandatory clearing across derivatives users, and margin hikes would not in a stressed market be confined to specific transaction types. Moreover, it would not just be a single CCP responding to the crisis: all CCPs are likely to follow suit, even if they are not themselves managing the default. For all these reasons we may conclude that any initial margin increase would use the higher figure as the multiplicand. We could therefore expect haircut-related initial margin increases from CCPs to amount to a demand for further

\footnotetext{
${ }^{16}$ Khwaja appears to have included the replenishment obligation of LCH clearing members in the "member funded" rather than the "member committed" category. We have readjusted his figures accordingly.

${ }^{17}$ Insofar as the CCPs in question have different default funds for different products, the figure given will be an overstatement of the amount at risk. But (i) the non-derivatives default funds are relatively small; and (ii) other derivatives-clearing CCPs could be added into the amount.
} 
collateral of around US $\$ 25$ billion, if the population of surviving clearing members worldwide experiences another average 5 percent hike. ${ }^{18}$

Initial margins required under the new Basel requirements for uncleared transactions have been estimated by ISDA (2012) and by Khwaja (2017). ISDA (2018) report that the top20 firms posted US\$31 billion in initial margins on uncleared transactions in 2017; these top20 firms represent "phase 1" of the roll-out of the Basel requirements, and numbers may rise as more firms are brought into scope. According to Khwaja, approximately US\$260 billion could be posted on such trades, giving a haircut-related increase of US\$13 billion across the whole market, though the bulk of this is likely to be concentrated on the banks - which will include the top-20 analyzed by ISDA which have entities acting as clearing members. ${ }^{19}$

We consider that the increase in initial margin requirements stemming from haircut changes is likely to be the minimum change: other factors in the stressed market may increase the demands, depending on the nature of the collateralized derivatives portfolio in question. So, we consider that the haircut-driven increase in demand for HQLA on margined uncleared portfolios estimated as above is conservative.

Next, we must add on the LCR-driven requirement for firms to hold additional HQLA in respect of initial margin posted. The requirement is to hold HQLA of 20 percent of the value of initial margin consisting of "level 1" assets: margin hikes will mean that firms have to obtain and set aside an extra amount ${ }^{20}$ of US $\$ 0.7$ billion of HQLA to satisfy LCR requirements.

\section{Loss of Receipts: Defaulted Master Agreements}

As regards the various master agreements which the defaulter has for its uncleared derivatives business, the question is what is the potential size of lost variation margin payable by the defaulter?

\footnotetext{
${ }^{18}$ It can be argued that margin calls related to cleared "client" positions can be passed on to clients. While this is true, the fact remains that the margin call will be there and will have to be satisfied from the available pool of eligible margin assets somehow, regardless of whether it is the clearing members or their clients that meet the call. As some clients may not be financial institutions with a ready inventory of eligible securities, the demand will ultimately need to be met by the financial sector.

${ }^{19}$ We do not consider the possibility of reduction in net open interest as a realistic mitigant for margin calls in such extreme conditions as we hypothesize. This is because, in our scenario, a CCP is unable to reduce its own book of defaulted positions through established auction and disposal processes; it follows that new offsetting trades, which would have exactly the effect that the CCP has been unable to achieve, are not at such a time being agreed and put into clearing.
}

${ }^{20}$ We estimate the proportion of LCR-eligible HQLA which is "level 1" to be approximately 75 percent. This is based on the assumption that collateral which is eligible under EMIR is (by and large) "level 1" standard. The ECB (2014) gives data for the available amounts of EMIR-eligible and LCR-eligible (i.e., including both "level 1 " and "level 2" assets) collateral. We therefore assume for our calculations that margin posted at CCPs is predominantly "level 1" and that 25 percent of uncleared transaction collateral is "level 2"' and subject to the 20 percent LCR requirement. 
It is difficult to assess the extent to which market counterparties will have successfully closed out their master agreements. In the case of Lehman Brothers, the close-out and settlement process took many months (Fleming and Sarkar, 2014). Market participants found that contractual rules purporting to limit the amount of time available for close-out and position valuation to be unworkable when market liquidity was highly impaired immediately after Lehmans' bankruptcy filing (cf. Bryceson, 2010). ${ }^{21}$

We conclude that, in a highly stressed market, a surviving counterparty would not be able to carry out a smooth and timely valuation of its uncleared transactions with a major defaulter. From an LCR standpoint, the counterparty will have to compute its expected lost net variation margin inflow over the coming 30 days. $^{22}$

To estimate the amount of unreceived variation margin due, after the date of default, from a defaulter to the counterparties who have terminated, but not yet resolved, their portfolios of uncleared derivatives transactions, we have drawn on two sources. The first is the actual experience of the Lehman Brothers collapse in 2008. To introduce this subject, we should first observe that in 2008 it was not common practice (and between top-12 banks virtually unheard-of) for there to be exchange of initial margin in relation to uncleared derivatives transactions, though variation margin would normally be recalculated and exchanged every business day. We should also note that central clearing of derivatives, while not mandatory, was in place, and Lehman had portfolios of cleared products at both LCH and CME. Finally, we note that the size of Lehman's derivatives portfolio, expressed as the "notional principal," was US\$35 trillion, comparable to the "notional principal" of the top four United States (U.S.) banks today, around US\$38 trillion each (OCC, 2018).

The available data on the claims against the Lehman estate suggest that derivatives claims filed were in the range US\$45 billion (Summe, 2012) to US\$51 billion (Lubben, 2014), of which US\$22 billion were concentrated among the top 13 bank counterparties ${ }^{23}$ (Summe, 2012; Fleming and Sarkar, 2014, Table 2 panel D). The quantum of claims actually allowed to rank in the bankruptcy were lower: Fleming and Sarkar (2014, Table 3 panel C) give a success rate of 47.4 percent to these claims. That analysis suggests that the total loss, not covered by margin, experienced by the market, was US $\$ 10.3$ billion for the top-13, so maybe around US\$20 billion across the whole market. However, there was an element of compromise in the way the settlement values were reached, which may indicate that the original amounts claimed were not all unreasonably inflated (cf. Summe, 2012, Fleming and Sarkar, 2014); on the other hand, a "claim" may include matters unrelated to the actual value of the transaction, under standard default-loss computation clauses in industry

\footnotetext{
${ }^{21}$ Cont (2018) observes that the post-default period of risk is variable depending on the size of the positions, rather than the type of instruments being processed. Cont also criticizes the distinction between the margin period of risk allowed to CCPs (5 days) and that applicable to uncleared transactions (10 days) as artificial, since it should not be assumed that the liquidity of the market for offload of cleared transactions is greater than that of uncleared, simply because there was high liquidity in pre-default times for a particular product.

${ }^{22}$ Under Basel III rules, banks have to identify the largest net 30-day collateral outflow observed during the preceding 24 months. As the effects of a major default feed into the calculation, we envisage that the most recent post-default days' experience, with an un-closed-out defaulted counterparty, will upset previous calculations of LCR based on live counterparties over 24 months.

${ }^{23}$ Summe states that the US\$22 billion was divided among 30 counterparty entities. But many of these were affiliated, so the 30 entities condense to 13 unaffiliated bank groups (Fleming and Sarkar, 2014, p. 186).
} 
documentation. Overall, one might conclude that the actual transaction-related losses were somewhere in this range, maybe US\$30 billion across the whole Lehman-facing bilateral market.

If we assume that, in September 2008, Lehman was up-to-date with its variation margin payments immediately before its default, then those losses represent the change in value of the portfolios of counterparties as they moved into the money after the last transfer of variation margin: the sums which - had it not failed - Lehman would have covered by further variation margin transfers in the post-default period. Although much has been made of the long time it took to settle Lehman's bilateral derivatives book (Cunliffe, 2018; Summe, 2012), a distinction should be made between settlement and quantification: banks were able to quantify their claims with reasonable alacrity once the markets stabilize. Thus, the losses claimed may represent a capped estimate of the variation margin forgone in the post-default period.

The alternative approach to quantifying lost variation margin is based on the analysis of Heath et al. (2015). ${ }^{24}$ Using a 2012 (and thus moderately stable market conditions) dataset, they estimate the expected exposures of banks, given the transfer of initial margin to cover expected losses at 99 percent confidence, to be US\$1 billion, and uncovered losses which might be experienced in extreme conditions (2.67 standard deviations) to be a further US\$93 billion..$^{25}$ A conservative estimate of the total variation margin due from a major defaulter after its default is to take one-twentieth or more of this market total, since OCC data consistently show that the top few banks are responsible for the majority of volume and exposures in this market. That approach gives us a figure of around US\$5 billion in lost variation margin due from a single bank such as our notional defaulting clearing member, post default. ${ }^{26}$

We do not offer a view on whether the theoretical or empirical approach is preferable. However, we suggest that the actual whole-market demand for HQLA, resulting from the application of LCR requirements on defaulted but unsettled bilateral derivatives portfolios in the circumstances of a major default, could fall somewhere within the limits indicated by these amounts. For our summary, we choose US\$12 billion, the mid-point between the theoretical and empirical numbers, on the grounds that the theoretical dataset may underestimate volatility in an extreme scenario, and that the historical Lehman data exaggerate the losses which might be experienced in the changed environment in which banks now operate.

\footnotetext{
${ }^{24}$ We follow their "Scenario 1" approach. The dataset is drawn on a BIS study of 41 banks, though the greater part by far is contributed by a much smaller number of global systemically important banks.

25 Tables 5 and 6, respectively.

${ }^{26}$ This may be compared with the figures given by Heath et al. for expected exposures if there were no collateral coverage at all: US\$177 billion over ten days, or about US\$9 billion of derivatives claims against a top-12 bank. Perhaps US\$9 billion is a comparator for the empirical uncollateralized Lehman's figure of somewhere around US $\$ 30$ billion, which indicates to us that it is difficult to compare numbers drawn from stable-market datasets with troubled-market actualities.
} 


\section{Loss of Receipts-VMGH}

As regards the implementation of VMGH, we observe from $\mathrm{LCH}$ data that the average VM payment daily by all 55 Swapclear clearing members to LCH is US $\$ 3.7$ billion. Although there is a historical study of the failure of a CCP in the 1970s, which appeared to involve the implementation of VMGH (Bignon and Vuillemy, 2018), there is no data on the likely duration of VMGH in a modern, OTC derivatives $\mathrm{CCP}$; we must estimate the duration of a period of VMGH ourselves. ${ }^{27}$ We envisage that a CCP would only have recourse to VMGH in a very extreme case: if other means of managing the problem, without causing damage to the key stakeholder base which provides the overwhelming substance of risk capital to the CCP, were available, it would be taken. So, we have to assume that a period of VMGH may endure, possibly for as long as a week, and that the defaulter's positions being managed continue to fall out of the money (from the CCP's perspective). On this simplified scenario analysis, market participants collectively are unlikely to have to bear VMGH-related losses of more than US\$18.5 billion in the week following a catastrophic default. ${ }^{28}$

The analysis indicates that firms will need to have a view of how long a period of VMGH may last. There are no statutory time limits in the existing United Kingdom (U.K.) or proposed EU regulations on "recovery" programs activated by CCPs. The rulebook of LCH does have a time limit of 10 business days, which can be extended by a further 10 business days by clearing member vote. ${ }^{29}$ However, it might be assumed that the regulator would intervene in a case where the $\mathrm{CCP}$ has struggled to regain control after an entire week of VMGH (cf. Cunliffe, 2018), and pressure from survivors is likely to build. We have therefore taken a week as being the likely tolerable period of VMGH.

For the purposes of calculating the LCR impact of VMGH, the shortfall in expected cash inflow would thus be US $\$ 18.5$ billion across the market, imposing an immediate demand for HQLA of that value on the day after VMGH comes into play. These figures should be viewed as being a minimum amount of the impact of VMGH across the population of gainers: in post-default conditions, price volatility might be expected to rise, with the consequence that variation margin amounts might rise accordingly. However, we have assumed that it is unlikely that more than one CCP would need to implement VMGH simultaneously.

\footnotetext{
${ }^{27} \mathrm{LCH}$ has rules (section CS4 of its Default Rules) which limit the extent to which LCH can impose VMGH. If an individual clearing member suffers VMGH equal to twice its default fund contribution (or GBP 200 million, if higher), or VMGH endures for 10 days, it is only permitted for VMGH to continue with the approval of a clearing member vote, and then the ceilings are doubled. With the support of a clearing member vote, LCH could in theory apply variation margin gains haircuts to its surviving clearing member population, over a threeweek period, which could come in at somewhat below $4 *$ default fund size (US\$26 billion approximately).

${ }^{28}$ Our analysis assumes that it is irrelevant that a proportion (based on LCH's quantitative disclosures, it may be around 50 percent) of a clearing member's business is cleared client trades. Certainly, a clearing member will pass on the impact of a variation margin haircut to its client (cf. footnote 18); but this does not "solve" the problem for the market as a whole, since the haircut causes a real loss to another market participant. Based on LCH data, about 50 percent of initial margin received is for gross-margined client transactions, the other 50 percent for net-margined transactions which are preponderantly house trades. VMGH ought not to operate differently between gross and net accounts. See also footnote 27 for quantitative analysis.

${ }^{29}$ LCH Default Rules, section CS4.
} 


\section{E. Overall Impact of the Default on HQLA Requirements}

The overall-market impact of the various demands for HQLA triggered by a major, difficult default would appear to be the sum of the items estimated so far, as shown in Table 2. This amount, of about US\$90 billion, can be compared with the amount of HQLA held for LCR purposes by top-12 banks, according to their 2018 regulatory returns, which is around US $\$ 350$ billion each. ${ }^{30}$ The number might also be compared with the total amount of collateral posted by top-20 firms in respect of derivatives in 2017 , calculated by ISDA to be US\$325 billion (ISDA, 2018).

We should comment on the possibility of collateral actually being released into the market, thereby easing supply, during the post-default period. ${ }^{31}$ As it manages the default, the affected CCP might be expected to have released into the market the defaulter's own initial margin, which will constitute HQLA However, a successful close-out like this means there would be no need to invoke VMGH. If, instead, VMGH is ongoing, the CCP will not have released the defaulter's collateral as the positions have not been closed out: the two scenarios are mutually exclusive. The same argument applies to the un-closed-out bilateral portfolios of the defaulter. So, if VMGH is in effect, it cannot be assumed that there would be an easing of collateral supply; and in any event the amount in question would not be of significant help. The position is different for CCPs which have not needed to invoke VMGH for default handling. Such CCPs may be able to liquidate margin and default fund assets.

Over the period since the financial crisis, a tightening of the "collateral supply" has been observed. The "fair value of securities received as collateral that is permitted to be sold or repledged" by global banks was approximately US\$10 trillion in 2007 but has declined in recent years to about US\$6 trillion. But this is turning around: while in Europe, HQLA may remain in short supply (although asset purchases will soon stop), the opposite is true in the U.S.: Also, collateral velocity is now inching higher for the first time since the Lehman crisis. (see Box 1). U.S. dollar-denominated HQLA should be able to satisfy much of the worldwide HQLA demand.

\footnotetext{
${ }^{30}$ The average unweighted HQLA amount, according to the most recent available regulatory disclosures made by Barclays, Citi, Goldman Sachs, HSBC, J.P. Morgan, and Morgan Stanley as at June 2018 was US\$362 billion. It is possible that the value of HQLA may fall during a crisis, but we not factored that into this analysis. [Basically a "drop in HQLA" due to a crisis-related haircut change at a CCP (e.g., a repeat similar to European periphery, 2011 crisis) may be optical since banks (especially the GSIBs) mark-to-market HQLA. So even if a large CCP marks higher haircuts due to a crisis, GSIBs can sell the HQLA at market prices, and post cash, or purchase other HQLA that is not affected by a CCP's haircut schedule. Furthermore, in parallel, there may be official sector (e.g., a central bank) substitution that is likely to allow swapping into other HQLA that it is preferable for a GSIB than an adverse CCP haircut matrix.] In extreme conditions, supervisors may allow banks to adjust their LCR-related holdings of HQLA. Central banks may also take action to stabilize the market in a crisis. However, banks would be ill-advised to rely on these possibilities.

${ }^{31}$ For completeness, we should also mention that the LCR calculation would be different if the bank experienced substantial inflows: the largest 30-day move could, theoretically, be an inflow. We have not modeled this possibility, which strikes us as unlikely during a period of extreme market stress.
} 


\section{Table 2. Effect of Major Default on HQLA Requirements}

\begin{tabular}{|c|c|c|c|c|}
\hline \multicolumn{2}{|r|}{ (U.S. dollars in billions) } & \multicolumn{3}{|c|}{$\begin{array}{l}\text { LCR-Related } \\
\text { Demand for } \\
\text { HQLA }\end{array}$} \\
\hline 1. & $\begin{array}{l}\text { Default fund replenishment (multi- } \\
\text { CCP) }\end{array}$ & - & 22 & 22 \\
\hline 2. & $\begin{array}{l}\text { Initial margin increases (multi- } \\
\mathrm{CCP} \text { ) }\end{array}$ & 25 & - & 25 \\
\hline 3. & $\begin{array}{l}\text { Initial margin increases (uncleared } \\
\text { market) }\end{array}$ & 13 & 0.7 & 13.7 \\
\hline 4. & $\begin{array}{l}\text { Variation margin foregone (closed- } \\
\text { out but unvalued bilateral trades } \\
\text { with defaulter }\end{array}$ & - & 12 & 12 \\
\hline 5. & VMGH (single CCP) & - & 18.5 & 18.5 \\
\hline Tot & & & 53.2 & 91.2 \\
\hline
\end{tabular}

Source: IMF staff estimates. 


\section{Box 1. The Demand/Supply of Global HQLA-the Macro Picture via Collateral Reuse Rate}

As of end-2017, the pledged collateral received by the major banks that could be onward re-pledged in their own name was US\$7.5 trillion, an increase of 25 relative to end-2016-see figures. Most global banks, and a couple of newcomers from Canada, were instrumental in this increase, after a decade of approximately US\$6 trillion market for pledged collateral.

Pledged Collateral Received by U.S. Banks (top panel) and European Banks (bottom panel)

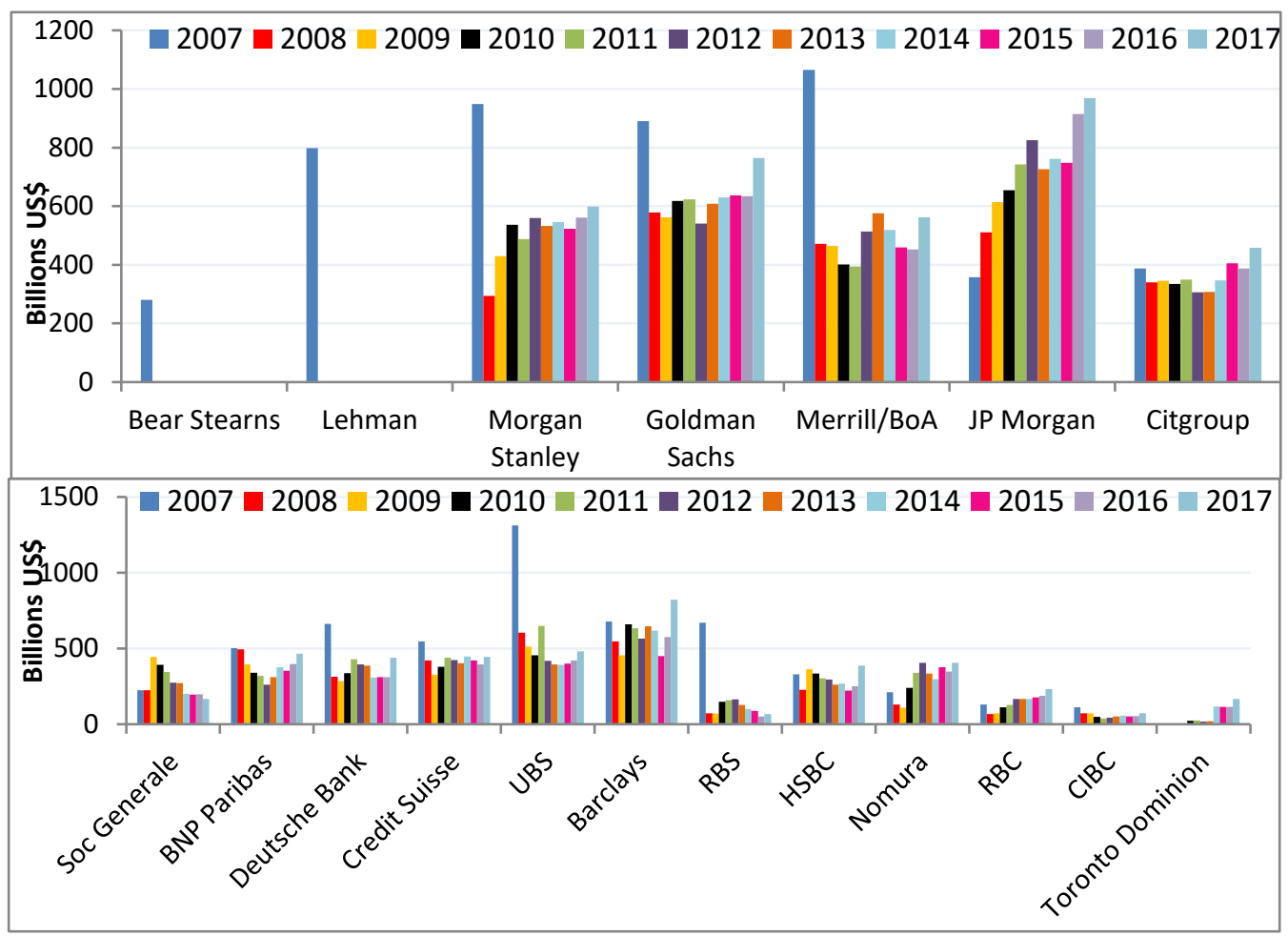

For global banks that peddle pledge collateral, there are two main sources: non-hedge funds and hedge funds Non-hedge fund data suggests pension, insurers, official sector and asset managers had US\$1.5 trillion in securities on loan (without secondary market churning). The other source of source for pledged collateral are hedge funds with AUM of US\$3.0 trillion (end-2017). Using methodology of Singh (2011) and technical factors such as long/short ratio, and rate-cycle related hedging, we estimate that US\$2.2 trillion collateral was pledged to the major banks from the hedge funds. In summary total pledged collateral from non-hedge funds source (US\$1.5 trillion) plus from hedge funds (US\$2.2 trillion) is US\$3.7 trillion. Arithmetically, the velocity of collateral for end-2017 was about US\$7.5 trillion/ US\$3.7 trillion, or just over 2.0-a first time increase since the Lehman crisis; this suggests that dealers have optimized or reshuffled their balance sheet transactions in light of the new regulations and central bank QE. While in Europe, HQLA continues to be in short supply (Bund repos are in the negative 50 bps range), the opposite is true in the U.S. where GCF (collateral rates) is close to 2 percent (200 bps) at present. U.S. dollar-denominated HQLA should be able to satisfy much of the worldwide HQLA demand. Market depth may be sufficient, under current demand-supply) conditions, to absorb a demand for approx.

US\$100 billion of HQLA that is estimated in this paper (re the "morning after.") 


\section{CONCLUSIONS}

A clearing member will suffer a number of hits to its prudential position on the "morning after" a big default of another clearing member. Of these the most challenging of the prudential issues - albeit not the most challenging question of all — for a clearing member is the increase in its liquidity coverage requirement. The surviving clearing members will need to lay hands on highly-liquid assets (HQLA) to cover deemed or assumed cash outflows which spike markedly at this point.

It has been observed that "high-quality collateral ... is in high demand in the private market when there is stress in the financial system." Further, "since mid-2015, there appears to be a scarcity of safe assets in the euro area even though there is no flight to safety because of a financial crisis" (Corradin et al, 2017). Collateral is inherently pro-cyclical, and our study shows that market stress following a major default could suddenly and markedly increase demand for HQLA in a marketplace where supply is already constrained; if the underlying causes of the default relate to macroeconomic conditions, the demand would add further procyclicality.

We also note that prudential standards have tended to favor the use of cash as margin by clearing members in respect of cleared client business. Clients with securities collateral will typically repo out securities in order to provide cash, which on receipt by the CCP is likely to be deposited with the central bank (e.g., Fed offers IOER, a preferred rate for depository institutions, to CCPs also). ${ }^{32}$ So, the push towards mandatory clearing by clients already tightens money supply, since cash deposited as margin is not available to the CCP or the wider market.

Factors which restrict the collateral supply may thus amount to a tightening of quasi-money supply, whether this is intentional policy or not. At times of stress following a major default (as in the scenario we hypothesize) it is unusual to tighten money supply. Yet our observation is that the consequences of a major default may have precisely that effect.

However, the fear that the market may not cope with the demand may be overstated. While in Europe, HQLA is in short supply, the opposite is true in the U.S.: collateral velocity is now inching higher for the first time since the Lehman crisis. U.S. dollar-denominated HQLA should be able to satisfy much of the worldwide HQLA demand. Market depth may be sufficient, under current monetary (including collateral-supply—see Box 1) conditions, to absorb a demand for up to US\$90 billion of HQLA. If that conclusion is correct, then the actions by CCPs following a default, which would pass through to clearing members and their clients, could be managed. VMGH would appear still to be the least unpleasant remedy for a CCP in difficulty (cf. Singh and Turing, 2018).

\footnotetext{
${ }^{32}$ Bank of England caps deposits by CCPs at the central bank. From a plumbing angle, if all cash pools have direct deposits at central banks (and skirt the plumbing), monetary transmission weakens as the ratio of money to collateral in market reduces.
} 


\section{References}

Armakolla, Angela, and Jean-Paul Laurent, CCP Resilience and Clearing Membership, https://papers.ssrn.com/abstract=2625579.

Baker, Colleen, 2012, “The Federal Reserve as Last Resort,” University of Michigan Journal of Law Reform, Vol. 46, pp. 69-133.

Bank for International Settlements, 2018, "Statistical Release: OTC Derivatives Statistics at end-December 2018," https://www.bis.org/publ/otc hy1805.pdf.

Bank of England, 2016, The Bank of England's Supervision of Financial Market Infrastructures-Annual Report, https://www.bankofengland.co.uk/-/media/boe/files/annualreport/2016/supervision-of-financial-market-infrastructures2016.pdf?la=en\&hash=B6494E0BF2714C131B684ABA2DCED7B4F1793968.

Bardoscia, Marco, Ginestra Bianconi, and Gerardo Ferrara, 2018, Multiplex Network Analysis of the UK OTC Derivatives Market, Bank of England Staff Working Paper No. 726.

BCBS, 2013, Basel Committee on Banking Supervision, Basel III: The Liquidity Coverage Ratio and Liquidity Risk Monitoring Tools, https://www.bis.org/publ/bcbs238.pdf.

,2015, Basel Committee on Banking Supervision and Board of the International Organization of Securities Commissions, Margin Requirements for Non-Centrally Cleared Derivatives, https://www.bis.org/bcbs/publ/d317.pdf.

Bignon, Vincent, and Vuillemey Guillaume, 2017, “The Failure of a Clearinghouse: Empirical Evidence," https://www.ssrn.com/abstract=2862673.

Brunnemeier, Markus K., and Lasse Heje Pedersen, 2009, "Market Liquidity and Funding Liquidity," Review of Financial Studies, Vol 22(6), pp. 2201-2238.

Bryceson, Antony, 2010, Lessons from Lehmans: "The 2010 GMSLA and the Short-Selling Regulation," Butterworths Journal of International Banking and Financial Law, Vol. 25, pp. 667-669.

Capponi, Agostino, Jessie Jiaxu Wang, and Hongzhong Zhang, 2018, “Designing Clearinghouse Default Funds,"

http://people.stern.nyu.edu/jhasbrou/SternMicroMtg/SternMicroMtg2018/Papers/designingC Hdefaultfunds36.pdf.

Carter, Louise, and Megan Garner, 2015, "Skin in the Game-Central Counterparty Risk Controls and Incentives,” Reserve Bank of Australia Bulletin, June Quarter 2015.

CFTC, 2016, “Commodity Futures Trading Commission,” CFTC Letter, No. 16-61. 
, 2018, “Proposal to Streamline Regulations for Swap Dealers," July 24.

CGFS, 2010, Committee on the Global Financial System, "The Role of Margin Requirements and Haircuts in Procyclicality," CGFS paper, No. 36, https://www.bis.org/publ/cgfs36.pdf.

, 2017, Committee on the Global Financial System, "Repo Market Functioning," CGFS paper, No. 59, https://www.bis.org/publ/cgfs59.pdf.

Cont, Rama, 2015, "The End of the Waterfall: Default Resources of Central Counterparties," Norges Bank Working Paper 16/2015.

https://papers.ssrn.com/sol3/papers.cfm?abstract id=2714374.

, 2017, "Central Clearing and Risk Transformation," Banque de France Financial Stability Review No. 21.

, 2018, "Margin Requirements for Non-Cleared Derivatives," ISDA White Paper, https://www.isda.org/a/cpmEE/Margin-Requirements-for-Noncleared-Derivatives-April2018.pdf.

Corradin, Stefano, Florian Heider, and Marie Hoerova, 2017, "On Collateral: Implications for Financial Stability and Monetary Policy,” ECB Working Paper No. 2017.

CPMI, 2017, Committee on Payments and Market Infrastructures and Board on the International Organization of Securities Commissions: "Recovery of Financial Market infrastructures," CPMI Paper No. 162, https://www.bis.org/cpmi/publ/d162.htm.

Cunliffe, Sir Jon, 2018, Central Clearing and Resolution - Learning Some of the Lessons of Lehmans," speech, https://www.bankofengland.co.uk/-/media/boe/files/speech/2018/centralclearing-and-resolution-learning-some-of-the-lessons-of-lehmans-speech-by-joncunliffe.pdf?la=en\&hash=954FF2E62AA3A5AB6ADCDEA88188FB6697F9B0CD.

Duffie, Darrell, 2014, "Resolution of Failing Central Counterparties," in Kenneth E. Scott, Thomas H. Jackson, and John B. Taylor, eds, Making Failure Feasible-How Bankruptcy Reform Can End 'Too Big to Fail' (Hoover Institution Press).

ECB, 2009, "OTC Derivatives and Post-Trading Infrastructures,"

ECB, 2014, "Collateral Eligibility and Availability."

European Commission, 2016: Proposal for a Regulation ... for the Recovery and Resolution of Central Counterparties, etc. COM/2016/0856 final, http://eurlex.europa.eu/resource.html?uri=cellar:b17255a7-b550-11e6-9e3c01aa75ed71a1.0001.02/DOC_ 1\&format=PDF. 
Fleming, Michael, and Asani Sarkar, 2014, "The Failure Resolution of Lehman Brothers," Federal Reserve Bank of New York Economic Policy Review, Vol. 20, No 2.

FSB, 2016, Financial Stability Board, "Essential Aspects of CCP Resolution Planning," http://www.fsb.org/wp-content/uploads/Essential-Aspects-of-CCP-Resolution-Planning.pdf.

, 2017, Financial Stability Board, "Guidance on Central Counterparty Resolution and Resolution Planning,” http://www.fsb.org/wp-content/uploads/P050717-1.pdf.

G20, 2009, "Pittsburgh Summit Declaration," http://www.g20.utoronto.ca/2009/2009communique0925.html.

, 2011, “Cannes Summit Final Declaration,” http://www.g20.utoronto.ca/2011/2011cannes-declaration-111104-en.html.

Heath, Alex, Gerard Kelly, and Mark Manning, 2015, "Central Counterparty Loss Allocation and Transmission of Financial Stress," Reserve Bank of Australia Research Discussion Paper 2015-02.

Huang, Wenquian, 2017, "Central Counterparty Capitalization and Misaligned Incentives," https://www.ecbforum.eu/uploads/originals/2017/yes/files/EFCB_2017 Wenqian\%20Huang PAPER.pdf.

IMF, 2007, "Financial Market Turbulence_Causes, Consequences, and Policies," Global Financial Stability Report.

ISDA, 2008, ISDA Margin Survey 2008, https:/www.isda.org/a/SeiDE/isda-margin-survey2008.pdf.

, 2017, Safeguarding Clearing: The Need for a Comprehensive CCP Recovery and Resolution Framework, https://www.isda.org/2017/09/18/safeguarding-clearing-the-needfor-a-comprehensive-ccp-recovery-and-resolution-framework/.

, 2018, ISDA Margin Survey Full Year 2017, https://www.isda.org/2018/04/25/isdamargin-survey-full-year-2017/.

J.P. Morgan, 2017, “A Balancing Act_-Aligning Incentives Through Financial Resources for Effective CCP Resilience, Recovery and Resolution," "https://www.jpmorganchase.com/corporate/news/document/Office-of$\underline{\text { Regulatory-Affairs-CCP-White-Paper.pdf? source=Office-of-Regulatory-Affairs-ISPgTile. }}$

Khwaja, Amir, 2017, "Margin for Non-Cleared Derivatives, "https://www.clarusft.com/margin-for-non-cleared-derivatives/. 
2018, "Swaps Data: Breaking Down CCPs'\$750 Billion Funding Bill,"

https://www.risk.net/comment/5443226/swaps-data-breaking-down-ccps-750-billionfunding-bill.

Koeppl, Thorsten V., 2012, "Central Counterparty Clearing: Incentives, Market Discipline and the Cost of Collateral," Bank of Canada Working Paper https://www.bankofcanada.ca/wp-content/uploads/2012/07/Koeppl-Thor-paper.pdf.

Lin, Li, and Jay Surti, 2013, "Capital Requirements for Over-the-Counter Derivatives Central Counterparties,” IMF Working Paper WP/13/3.

Lubben, Stephen J., 2014, "Lehman's Derivative Portfolio," https://papers.ssrn.com/abstract=2698234.

Markose, Sheri, Simone Giansante, and Ali Rais Shaghaghi, 2017, "A Systemic Risk Assessment of OTC Derivatives Reforms and Skin-in-the-Game for CCPs," Banque de France Financial Stability Review No. 21.

Miglietta, Arianna, Cristina Picillo, and Mario Pietrunti, 2015, “The Impact of CCPs' Margin Policies on Repo Markets," BIS Working Paper No. 515.

Murphy, David, 2017, "I’ve Got You Under My Skin: Large Central Counterparty Financial Resources and the Incentives They Create," Journal of Financial Market Infrastructures, Vol. 5(3), pp. 57-74.

Nahai-Williamson, Paul, Tomohiro Ota, Mathieu Vital, and Anne Wetherilt, 2013, "Central Counterparties and Their Financial Resources-A Numerical Approach," Bank of England Financial Stability Paper No. 19.

OCC, 2018, "Quarterly Report on Bank Trading and Derivatives Activities, Q4 2017," https://www.occ.treas.gov/topics/capital-markets/financial-markets/derivatives/dq318.pdf.

Paddrik, Mark, and H. Peyton Young, 2017, "How Safe are Central Counterparties in Derivatives Markets?” OFR Working Paper 1706.

Perkins, Christopher, Vijay Albuquerque, and Marian Rafi, 2016, "Central Counterparties Need Thicker Skins," Journal of Financial Market Infrastructures, Vol 4(3), pp. 55-63.

Singh, Manmohan, 2010, "Under-Collateralization in the OTC Derivatives Markets," Banque de France Financial Stability Review No. 14.

, 2013, "OTC Derivatives Market-Regulatory Developments and Collateral Dynamics," Banque de France Financial Stability Review No.17. , 2016, "Collateral and Financial Plumbing" (second impression, Risk Books). 
, and Dermot Turing, 2018, "Central Counterparties Resolution-An

Unresolved Problem,” IMF Working Paper WP/18/65.

Summe, Kimberly Ann, 2012, “An Examination of Lehman Brothers' Derivatives Portfolio Postbankruptcy: Would Dodd- Frank Have Made a Difference?" Chapter 4 in: Kenneth E. Scott and John B. Taylor (eds.), Bankruptcy Not Bailout (Hoover Institution, Stanford University).

Tucker, Paul, 2013, “Central Counterparties in Evolving Capital Markets: Safety, Recovery and Resolution," Banque de France Financial Stability Review No.17.

Turing, Dermot, 2016, Clearing and Settlement (Bloomsbury). 